\title{
PRÁTICAS DE ENSINO EPISTEMOLOGICAMENTE DIFERENCIADAS SOBRE A APRENDIZAGEM DO CORPO HUMANO
}

\author{
TEACHING PRACTICES EPISTEMOLOGICALLY DIFFERENTIATED ABOUT \\ HUMAN BODY LEARNING
}

\author{
Rosália M. R. de Aragão ${ }^{1}$ \\ Patrícia M. S. Figueiredo ${ }^{2}$ \\ Maria Rosa Q. Bomfim ${ }^{3}$
}

\begin{abstract}
O que ainda, e sobretudo, é necessário, para conceber o vir a ser histórico, é substituir por uma concepção complexa a reinante concepção simplista.

Edgar Morin
\end{abstract}

\section{RESUMO}

Como ensinar sobre O CORPO HUMANO de maneira epistemológica e pedagogicamente diferenciada? Como abandonar aspectos estagnados e estagnantes do ensino tradicional, tais como, a fragmentação, o congelamento do real, o detalhismo excessivo e outros, quando se trata de estudar o nosso corpo? Estas são algumas das questões que mantivemos presentes ao realizar grande esforço para fugir à influência da nossa 'formação ambiental' - com todas as marcas adquiridas dentro e fora da escola - e buscarmos uma visão mais ampla do nosso corpo em funcionamento... em constante interação com o ambiente. Dentre as marcas do tipo mencionado de formação que geralmente recebemos na Universidade, e precisamos superar, destacam-se os inúmeros contatos com corpos dissecados e desfigurados, corpos que não se assemelhavam a corpos humanos porque pareciam jamais ter abrigado vidas. Corpos inertes ou estáticos, utilizados como meros 'materiais didáticos', permitiram e permitem a muitos professores em formação certo tratamento no ensino apenas tendo em vista a memorização, por parte de alunos e alunas, de uma infinidade de "nomes complicados" e a estruturação por definição e classificação - de sistemas e do que se denomina organismo biológico. Para tanto, buscamos nos inspirar em três metodologias alternativas de ensino que abordam esse assunto em uma perspectiva construtiva. Nos três estudos enfocados, é possível observar que estiveram presentes princípios próprios de uma abordagem atual de ensino - usualmente denominada 'construtivismo' - dentre os quais os seguintes : a) o respeito às idéias prévias dos alunos; b)a visão de que o conhecimento não é algo pronto e imutável, e c)o acompanhamento constante da re-elaboração dessas idéias no decorrer dos processos de ensino e de aprendizagem nas aulas de Ciências.

\footnotetext{
1 Doutora em Educação e Pós-Doutora em Educação em Ciências e Educação Matemática pela Universidade Estadual de Campinas - UNICAMP. Docente e Pesquisadora da UNICEUMA.

${ }^{2}$ Doutora em Ciências Biológicas pela Universidade do Estado de São Paulo - UNESP. Docente e Pesquisadora da UNICEUMA.

${ }^{3}$ Doutora e Pós-Doutora em Ciências Biológicas pela Universidade do Estado de São Paulo - UNESP. Docente e Pesquisadora da UNICEUMA.

AMAZÔNIA - Revista de Educação em Ciências e Matemáticas V.8 - no 15 - jul. 2011/dez. 2011, p. 61-74.
} 


\begin{abstract}
How could we teach about THE HUMAN BODY as a different way, in both epistemological and pedagogical approaches? How could we leave behind stagnant as well as stagnating aspects of traditional way of teaching, such as the fragmentation/segmentation of contents, the far away reality, the excessive use of details or else, whenever learning about our own body? These are some of the questions we have considered when trying to escape the bad influence which came from our "environment formation" - putting it on all the marks we have acquired inside or even outside school - trying to overview as meaning our body working...in constant interaction with the surrounding ambient. Among those pointed kind of formation marks we frequently acquire from studying at the University - which need to be transcended here we come to detach those innumerable contacts with both anatomized and misfigurated supposed human bodies' which didn't even look like actual human bodies, because they could never seem to have sheltered life inside themselves. They were inert as well as static bodies, only used as a such of vain "didactic materials" that could/can permit many teachers on their educational formation to focus a certain teaching approach which only seeks both the students' memorization of an infinitude of "complicated words", and to structure the systems by several procedures of nouns definition and/or classification - as part of the so called biological organism. In order to do a different way of teaching, we have based our approach on three alternative teaching methodologies which focus these matters under a constructive perspective. On those three focused studies, it is possible to observe that some very principles of a present day teaching approach were there considered to achieve some of them: the respect for the students' previous ideas; the understanding about knowledge as something that is not established for good but as ever changeable and, at last, the constant accessory over the students' re-building of some ideas along the teaching and learning processes in the Science classes.
\end{abstract}

Key-words: Science Education - Teaching Models - Constructive Education

\title{
INTRODUÇÃO
}

Como ensinar sobre O CORPO HUMANO de maneira epistemológica e pedagogicamente diferenciada? Como abandonar aspectos estagnados e estagnantes do ensino tradicional, tais como, a fragmentação, o congelamento do real, o detalhismo excessivo e outros, quando se trata de estudar o nosso corpo?

Estas são algumas das questões que mantivemos presentes ao realizar grande esforço para fugir à influência da nossa 'formação ambiental' - com todas as marcas adquiridas dentro e fora da escola - e buscarmos uma visão mais ampla do nosso corpo em funcionamento... em constante interação com o ambiente.

Dentre as marcas do tipo de formação que geralmente recebemos principalmente no curso de nossa formação universitária - foram passíveis de modificações justamente aquelas adquiridas em aulas de anatomia e de fisiologia humana, nas quais tivemos inúmeros contatos com corpos dissecados e desfigurados, corpos que não se assemelhavam a corpos humanos porque, em seu estado de rigidez, pareciam jamais ter 
abrigado vidas. Corpos inertes ou estáticos que, devido à sua utilização como 'material didático', permitiram e permitem a muitos professores em formação, certo tratamento no ensino apenas tendo em vista a memorização, por parte de alunos e alunas, de uma infinidade de "nomes complicados" e a estruturação - por definição e classificação - de sistemas e do que se denomina organismo biológico.

Foi justamente essa visão restrita de organismo biológico, ou seja, do corpo como uma soma de sistemas funcionando em conjunto (SANTOS, 1997) que, desde logo, no início, precisamos fazer grande esforço para abandonar. Caso contrário, continuaríamos ignorando as dúvidas e idéias equivocadas dos alunos, consideradas imprescindíveis para realizar uma prática pedagógica interativa e eficiente em termos de aprendizagem significativa, pautada na crença de que o domínio exclusivo de conhecimentos ligados à área biomédica pode ser suficiente para a realização de um ensino eficaz ou atingente para aquisição de conhecimentos sobre o Corpo Humano. Assim, continuaríamos a ouvir comentários de alunos e alunas que pareciam acreditar não ter capacidade para aprender "tais assuntos", posto que, com frequiência, se expressavam assim: Eu já estudei essas coisas de corpo humano, mas eu não me lembro de nada... Eu sei que tem até nome de 'rádio'... sei lá... nos nossos ossos... como comentou um aluno da $1^{\circ}$ ano do Ensino Médio. Ou, então, continuaríamos vendo os nossos alunos buscando respostas para as dúvidas ligadas ao seu corpo em "revistas femininas", especialmente naquelas voltadas para o público adolescente... e em outros meios de comunicação nem sempre confiáveis!

Ao assumirmos certo 'espírito de mudança' havíamos percebido que realizávamos uma prática narcisística em nossas aulas, quer dizer, era como se estivéssemos 'dando aula para nós mesmas', uma vez que as nossas insistentes explanações sobre aspectos anatômicos ou fisiológicos - muito embora pudéssemos torná-los cada vez mais claros para nós próprias - não tinham significado algum para os nossos alunos. Constatamos, então, que o ensino de corpo humano que nós realizávamos - independente de ser com ou sem utilização de material didático-pedagógico conservador ou dito inovador - não se diferenciava daquele tipo de 'transmissão-recepção' de conteúdos a serem decorados para a prova e, depois (claro!), esquecidos, dada a ausência de relação com a vida de nossos alunos e alunas. Tratava-se, claramente, de um conteúdo sem significado, portanto inútil, para qualquer aluno ou aluna e, sendo assim, reforçava a idéia de que é difícil aprender ciência, como diz BIZZO (1998: 92). Isto porque, em função do ensino usual, a aprendizagem continuava pautada na aquisição de conceitos mecanicistas e em dados pontuais, a exemplo do que expressa o autor referido: Às vezes tem-se a impressão de que os alunos devem aprender nomes mágicos, como "visão" e "audição", como se assim passassem a ver e ouvir melhor.

À semelhança deste caso do 'ensino dos sentidos', pelo qual se oferece um tratamento do assunto que simplesmente ignora a qualidade (material ou sentimental) daquilo que se vê ou ouve, de como as funções dos sentidos se complementam e de como cada indivíduo procura realizar estas ações (ver e ouvir), muitos outros assuntos eram por nós tratados de maneira a restringir, demasiadamente, as possibilidades de exploração do conhecimento. Era cada um deles, portanto, tratado como 'um assunto a mais' do currículo escolar que deveria ser "ensinado", de forma quase absurda porque independente de alunos e alunas.

Por razões como essas, começamos a ver necessidade de abordarmos diferenciadamente os assuntos do Corpo Humano, em um primeiro momento de mudança, ainda na perspectiva de corpo biológico, no entanto, já abrangendo aspectos ligados, entre outras coisas, à afetividade, à sexualidade e à estética, dimensões geralmente atribuídas à cultura. Tornávamo-nos cientes de que isso possibilitaria a abertura necessária para a 
emergência de questões polêmicas para os alunos e as alunas - mas pedagógicas ou educativas - tais como sexo, aborto, homossexualismo... Em razão de tais assuntos apresentarem-se geralmente polêmicos, talvez por isso mesmo sejam omitidos ou tratados de forma superficial pelos professores em aulas, muito embora façam parte daquilo que há de mais significativo para os nossos alunos e alunas adolescentes : basta iniciarmos a abordagem de um desses assuntos relativos ao 'corpo' para que eles e elas comecem a fazer perguntas e a mencionar situações vivenciadas em seu cotidiano. As manifestações intensas do alunado sobre assuntos que lhe dizem respeito são, freqüentemente, configuradas como uma busca de oportunidades de reflexão e de 'solução' de questões para eles e elas - relacionadas especialmente à sexualidade - que possam deixar claro aquilo que cada um e cada qual precisa conhecer/entender quer a respeito do seu próprio corpo quer do corpo do outro.

Pensando, por nossa vez, nas reflexões desejáveis de serem feitas coletivamente, vimos necessidade de essas serem cada vez mais críticas e aprofundadas o suficiente para possibilitar o abandono de muitas crenças infundadas, o abandono de idéias e de pontos de vista geralmente trazidos pelos nossos alunos à escola.

Algumas das muitas crenças carregadas por nossos alunos, dependendo da liberdade que eles encontrem nas aulas de Ciências, podem nem chegar a serem manifestadas ou podem ser ignoradas ou mesmo reforçadas pelo ensino oferecido, até por omissãa dos agentes pedagógicos do processo (MOHR, 1995, e BIZZO, 1998).

Enfim, tendo presente que a postura do professor e a maneira que ele tem de ver e relacionar-se com o próprio corpo são decisivas para aceitar (ou, pelo menos, para conviver com) uma diversidade de opiniões que podem ser contrárias às suas, resolvemos repensar os conceitos que já tínhamos consolidados sobre o Corpo Humano e investigarmos novas e educativas maneiras de abordá-lo nas nossas aulas de Ciências. Buscamos, pois, dar a imprescindível abertura para tratar e discutir questões do 'corpo humano' em aula.

Para tanto, buscamos nos inspirar em três metodologias alternativas de ensino que abordam esse assunto em uma 'perspectiva construtiva'. Nos três estudos enfocados - que passamos a apresentar na nossa versão - é possível observar que estiveram presentes princípios próprios de uma abordagem atual de ensino - usualmente denominada ‘construtivismo'. Esses princípios foram, sobretudo os seguintes:

o respeito às idéias prévias dos alunos;

a visão de que o conhecimento não é algo pronto e imutável, e

o acompanhamento constante da re-elaboração dessas idéias no decorrer dos processos de ensino e de aprendizagem nas aulas de Ciências.

No entanto, em cada um desses modelos de ensino, podemos observar diferenças no grau de inovação que cada autor assume e realiza, uma vez que o primeiro e o segundo (BANET e NÚÑEZ, 1992; e GUIDO, 1996) se mostram mais apegados ao cumprimento de um programa de ensino pré-estabelecido e o terceiro (RABELLO, 2000), apesar de ter definido em seu âmbito os seus objetivos de ensino e o caminho para atingi-los, parece não se vincular, pelo menos da maneira usual, a um programa previamente definido de ensino, mantendo-se atrelado a este.

\section{UM PRIMEIRO MODELO DE ENSINO}

Muitos temas desenvolvidos no âmbito deste modelo foram confrontados e definidos no decorrer do processo, em aulas, partindo das concepções inicialmente expressas pelos alunos da professora-autora e regente da classe tomada como locus de investigação, 
decorrentes de curiosidades, crenças e explicações pessoais para diversos fenômenos. Por exemplo, quando um de seus alunos do $5^{\circ}$ ano do ensino fundamental se manifestou a respeito de que "o antebraço teria o mesmo tamanho do pé", esta professora - como pesquisadora do ensino - estimulou a ocorrência de uma discussão a respeito desta questão, em classe. A partir daí, outros alunos acabaram apresentando suas crenças a respeito das proporç̃̃es do corpo, como a de que "a envergadura de uma pessoa seria correspondente à sua altura".

Depois disso, configurou-se um problema a ser investigado por todos os alunos, qual seja, as medidas do nosso corpo.

Dessa questão inicial, muitas outras surgiram, tais como : (a) as diferenças no tamanho de cada pessoa; (b) as diferenças nos tamanhos das partes do corpo de cada um; (c) a existência de uma maior igualdade ou diferença nas proporções de diversas partes do corpo, relacionando-as à fase de crescimento, etc.

Assim, utilizando-se de uma estratégia de ensino que, a nosso ver, visou e assegurou aprendizagem significativa por parte de alunos e alunas, foi efetuada uma sequiência de atividades próprias para a formação de um aluno-pesquisador do conhecimento, que implicava o seguinte:

\section{A manifestação das hipóteses dos alunos para as questões mencionadas (anotadas pela pesquisadora)}

tomada de medidas (pelos alunos) de várias pessoas de sua casa e das próprias medidas de seu corpo, com anotação da idade e sexo das referidas pessoas;

b) a construção de tabela classificatória comparativa com critérios: (i) tamanhos iguais; (ii) tamanhos próximos, permitindo uma diferença de até $2 \mathrm{~cm}$; (iii) tamanhos diferentes, quando a diferença fosse superior a $2 \mathrm{~cm}$ );

\section{Análise e discussão dos dados tabulados}

c) levantamento de diversas questões e hipóteses para aprofundamento do assunto, $\mathrm{e}$

\section{Busca de informações em fontes científicas sobre o assunto.}

Para finalizar, sem dar um valor maior às informações científicas como "as verdadeiras", a professora-pesquisadora abriu espaço para as manifestações conclusivas dos alunos, buscando analisar o redimensionamento de suas idéias, de suas aquisições de novo conhecimento.

\section{UM SEGUNDO MODELO DE ENSINO}

Outro modelo de ensino foi produzido pela parceria docente de uma professorapesquisadora com uma professora de $5^{\circ}$ ano do ensino fundamental, como 'professora da classe' que realizava práticas alternativas de ensino em aula. Para a prática interativa das duas professoras, houve necessidade de reestruturação da seqüência do programa usual de ensino elaborado pela professora do quinto ano no início do ano letivo, embora se mantivessem os temas previstos. Mas, ainda assim, apesar de buscar abordar e colocar em prática os assuntos pré-estabelecidos - para não fugir do seu programa -, a reformulação na sequiência de ensino e 
as relações estabelecidas entre os assuntos, abriram espaços para o desenvolvimento de temas muito mais ligados a certas manifestações de alunos e alunas. Um exemplo disso pode ser destacado quando da realização de uma prática de ensino em aula, envolvendo o estudo da anatomia e da fisiologia de uma minhoca, a qual foi trazida e dissecada pelos alunos sem o conhecimento prévio nem da pesquisadora nem da professora da classe. A minhoca era uma das espécies a serem abordadas no estudo comparativo que estavam realizando para trabalhar os processos de respiração, circulação, digestão, locomoção e fotossíntese, entre os seres vivos.

Além de tratar dos aspectos morfofisiológicos envolvendo os processos citados, a professora-pesquisadora - que participava regularmente das aulas - abordou questões ligadas aos procedimentos técnicos considerados "corretos", ou "mais apropriados' para se fazer uma dissecação de espécimes como a minhoca em questão. Com isso, pesquisadora e professora conseguiram realizar procedimentos ou abordagens de ensino que - conforme sugerem os Parâmetros Curriculares Nacionais (Brasileiros) - Ciências Naturais (1996) - precisa chegar a lidar com os conhecimentos nos seus aspectos conceituais, procedimentais e atitudinais.

É importante ressaltar que, no que diz respeito ao conhecimento científico que pode ser tratado em aulas de Ciências, é possível dizer que o segundo estudo, por nós considerado para gerar modelos de ensino (GUIDO, 1996), tem uma abrangência bem maior em relação aos outros dois aqui enfocados, uma vez que este não se restringiu ao entendimento de processos fisiológicos somente no ser humano. O tema do 'Corpo Humano' foi tomado como um referencial, foi o 'ponto de partida' ou um parâmetro importante para deflagrar o estudo, mas outros seres vivos, tais como o peixe, a minhoca, o sapo, os insetos e as plantas foram também considerados no estudo em foco, pelas professoras e pelos alunos, para compreensão de relações cognitivas de maior significação pela abrangência.

O trabalho foi iniciado com a elaboração de um 'mapa conceitual' dos sistemas e conceitos a serem estudados, para que tanto a professora quanto a pesquisadora tivessem maior clareza das idéias a serem por elas envolvidas no processo de ensino e de aprendizagem. Dessa forma, elas certamente teriam maior compreensão das dificuldades de aprendizagem que viessem a ser manifestadas por seus alunos. Isto se daria em função da maior ou menor complexidade dos conceitos a serem aprendidos, pela posição que cada um e cada qual viesse a ocupar, no modo de ver das professoras, na hierarquia conceitual, dada a sua maior ou menor inclusividade ou abrangência ideacional (Cf. AUSUBEL, 1968). Visualizaram, também, as relações existentes e aquelas possíveis de serem estabelecidas entre os conceitos por elas definidos para serem ensinados, de modo a tornar possível não só uma visão global do que queriam ensinar, mas também do necessário 'planejamento' do(s) tema(s) a ser(em) desenvolvido(s) nas aulas.

Depois disso, as práticas de ensino e de aprendizagem nas aulas envolveram atividades tais como as seguintes:

Execução de desenhos espontâneos, por parte de alunos e alunas, para expressarem 'esquemas corporais' - o corpo por dentro - seguidos de análise pela professora para identificação das idéias prévias dos alunos;

Uso constante de comparações do tipo 'O que há de igual, ou parecido, ou diferente, entre a respiração do homem e a do sapo ?';

Proposição de situação-problema para ser "resolvida" - ou estudada - por alunos e alunas, por exemplo: 'O aproveitamento do nosso alimento depende da nossa respiração?';

Atividades em grupo para discussões e comparações, com base nos desenhos realizados individualmente, até chegar a conclusões - mediadas pelas professoras - que 
expressassem a concordância do grupo na representação corporal, agora expressa por um 'desenho coletivo';

Anotações - por alunos e alunas em seus cadernos - das informações obtidas nas discussões e nas pesquisas realizadas em casa ou em aula sobre o assunto;

Elaboração de listas e tabelas relacionadas aos 'componentes do corpo';

Uso de observação para comparação de diferentes espécies de animais levados à sala de aula pelos alunos, seguida de produção de textos, isto é, de relatos das vivências em classe pelos alunos, expressando suas explicações para o assunto em pauta;

Produção coletiva de textos - organizada pela professora que os escrevia na lousa em função da interação com alunos e alunas -, textos esses conclusivos sobre o assunto ou que serviam de base para a realização de novas atividades.

Tanto nas estratégias de ensino do modelo de Guido (1996) como nas de Rabello (2000) utilizam-se também aulas expositivas, extremamente necessárias quando o conceito envolvido não é passível de observação direta, ou não propicie aprendizagem efetiva quando da descoberta ao aluno, conforme ocorre com os processos fisiológicos (NÚÑ̃Z e BANET, 1992).

\section{UM TERCEIRO MODELO}

O uso de aulas expositivas, como já referido, faz parte das estratégias de ensino de Núñez e Banet (1992), quando realizaram estudos ligados aos processos fisiológicos do ser humano, mais especificamente à 'nutrição humana'.

Esses estudos foram desenvolvidos em uma escola espanhola, com alunos na faixa etária de 13 a 14 anos, ou seja, em idades correspondentes às do oitavo e nono anos do ensino fundamental brasileiro.

Este estudo abordou a possibilidade de "caminharmos juntos" com o alimento pelo nosso corpo, observando a sua transformação nos diferentes órgãos e seu aproveitamento pelas células, proporcionando o conhecimento das estruturas que nos formam e de como elas interagem. Trata-se de uma prática de ensino de Ciências voltada para o conhecimento do processo de digestão e de sua interação com a respiração e a circulação que se aprofunda nos aspectos anatômicos e fisiológicos, contudo, ainda deixa de lado questões sociais e culturais que envolvem o nosso corpo humano.

Seus aspectos inovadores estão, no entanto, em tomar como referencial uma séria análise sobre as concepções de alunos e alunas, bem como de professores e professoras nesta área - foco de outros estudos desses mesmos autores (realizados em 1989 e em 1996) o nível do ensino e da aprendizagem de Ciências - em direção ao conhecimento científico. Assim, as pesquisadoras buscaram assegurar

a compreensão do Corpo Humano como constituído de partes interdependentes;

a compreensão da dinâmica das reações ocorridas - em níveis 'macro', isto é, 'a olho nu' e em níveis 'microscópicos' - bem como da maneira pela qual os diferentes alimentos são metabolizados, considerando que 'para estímulos externos diferentes temos reações também diferentes em nosso corpo'. 
As cinco etapas realizadas que, segundo as professoras-pesquisadoras proponentes, não têm que obedecer à sequiência aqui apresentada, envolvem aspectos tais como:

(i)a investigação das idéias prévias dos alunos;

(ii) a reestruturação de idéias no curso da interação de ensino e de aprendizagem;

(iii) a construção de novas/outras idéias decorrentes das várias interações, tais como, por exemplo, 'anatomia do sistema digestório'; 'decomposição das substâncias nutritivas contidas nos alimentos', bem como 'absorção dos produtos resultantes da digestão' ;

(iv) a aplicação ou uso das idéias novas construídas ou em construção por interação entre os alunos;

(v) a revisão coletiva de idéias novas, de outras e das iniciais que foram apresentadas pelos alunos e por professores.

No decorrer dessas etapas foram realizadas atividades interativas consideradas indispensáveis, a saber:

A exploração das idéias prévias dos alunos, através de desenho ou de outra construção material, que possibilitasse a eles, no caso referido, representarem os órgãos que formam o sistema digestório humano.

A partir das representações das idéias dos alunos sobre a anatomia do sistema digestório, por exemplo, foi solicitado que eles explicassem como nesse seu esquema o alimento caminha... Para tanto, houve utilização de maquetes, vídeos, etc., de modo interativo, para promover o conhecimento da estrutura destes órgãos, em particular do intestino delgado, visando o destaque da grande importância deste no processo da digestão. Além disso, fez-se uma exposição do processo de decomposição das substâncias nutritivas dos alimentos com o material produzido. Ao final, apresentou-se uma situação-problema aos alunos, tal como: 'Qual é o trajeto de um pedaço de pão - que seja por nós ingerido - dentro do nosso corpo?'.

Entre as atividades que estas autoras referidas desenvolvem - e que são geralmente comuns aos demais modelos de ensino realizados em uma perspectiva de construção do conhecimento por professores e alunos em interação - na qual os dois modelos anteriores também se situam, é possível destacar a ocorrência de ações e reações pouco comuns no processo de ensino e de aprendizagem em aulas de Ciências, tais como as seguintes:

\section{emissão de hipóteses individuais;}

debates sobre essas hipóteses nos grupos de trabalho de alunos e alunas;

compartilhamento com a classe dos diferentes informes ao final das atividades principalmente para socialização do conhecimento construído e sistematização oral e escrita deste conhecimento por todos os alunos e alunas em aula.

É interessante observar que, por se tratar, neste modelo, de uma estratégia utilizada em um nível de ensino mais avançado, no curso da escolaridade, os professores-pesquisadores se diferenciam dos anteriores quando visam as relações entre o sistema digestório e o circulatório, abordando, em termos mais específicos, o estudo da natureza das substâncias que podem ser absorvidas, lembrando que, para isso, os alunos precisam pretender adquirir um conhecimento mais amplo e adequado sobre os alimentos. Nesses termos, pode-se introduzir e considerar a digestão como um processo essencialmente 
químico. Sendo assim, abordam-se as funções dos sucos digestivos no processo digestório, em termos muito mais específicos. Contudo, vale ressaltar o seguinte:

Em cada etapa dessas atividades, precisa haver a complementação do assuntoalvo com as orientações e explicações do professor ou da professora, bem como com um maior apoio de material escrito ou audiovisual.

Um aspecto que pode aproximar dois dos modelos de ensino aqui apresentados - de NÚÑEZ e BANET e de GUIDO - é que os professores e a professora proponentes chegam a sugerir atividades para o estabelecimento de relações entre o sistema digestório humano e o de outros animais, para compreensão mais ampla de alunos e alunas, tão bem desenvolvidas pela professora-pesquisadora em seu estudo em parceria.

Outra aproximação entre os modelos de NÚÑEZ e BANET e de RABELLO, no caso, é percebida no que diz respeito a o sangue ser considerado o elemento unificador, integrador, para ensino do Corpo Humano, em uma visão global, ou seja, na perspectiva de o Corpo Humano ser visto pelos alunos funcionando como um todo integrado.

No decorrer da realização de suas atividades em sala de aula com seus alunos e suas alunas, a professora-pesquisadora referida por último constatou esta mesma importância do sangue, quando, por sua vez, o elegeu e o manteve como 'eixo' das aulas e do 'curso' sobre o Corpo Humano, nas suas aulas de Ciências.

Vale ainda deixar claro que, nas suas aulas, na sua prática de ensino, esta última professora-pesquisadora desenvolveu o tema sob enfoque em duas etapas, quais sejam :

1. Primeiro, com o tema ' $O$ alimento do corpo' - quando abordou assuntos que envolviam o sangue e suas funções, sua relação com o coração e especialmente a função da circulação sanguínea na 'homeostasia', isto é, na constante manutenção das condições físicas e das concentrações das substâncias dissolvidas no meio interno. Tratou de destacar o sangue como "peça-chave" para a manutenção desse sistema (homeostásico), devido ao seu constante bombeamento e difusão de líquido através da membrana dos capilares, no sentido sangueespaço intersticial e vice-versa. Para permitir essa noção, a autora desenvolveu debates em aula questionando os alunos e anotando suas respostas na lousa sobre perguntas tais como as seguintes : Em que situação podemos ver o sangue? O que é o sangue?, buscando, assim, conhecer para organizar (e questionar!) as idéias prévias de seus alunos e de suas alunas. Verificou que, nas respostas dos alunos, persistiu a idéia geral de que o sangue é essencial à manutenção da vida, pois nele está o alimento necessário para vivermos. Mesmo assim, a professora-pesquisadora realizou, ainda, outras atividades buscando significados do sangue "o conceito" - entre seus alunos. Para isso, eles realizaram consultas a diversos dicionários, fizeram questionamentos à sua professora e realizaram vários debates em aula. Ao final desta primeira etapa, foram explicitados os 'elementos-chave' que deveriam ser abordados, na continuação do estudo, pois esses configuravam as dúvidas e idéias equivocadas de alunos e alunas, as quais, por sua vez, foram tomadas como novos/outros 'pontos de partida' para uma segunda de abordagem desse tema.

2) Segundo, foi realizado - de forma interativa - um novo/outro estudo coletivo denominado 'A Representação Gráfica da Pulsação'. As atividades então realizadas, como já mencionamos, envolveram alunos e alunas em constante reflexão, observação e, portanto, em um processo dinâmico de conhecimento de seu próprio corpo, bem como dos corpos de seus colegas, de familiares e de pessoas próximas (parentes, vizinhos e amigos). Por isso, e com isso, houve a comparação de manifestações físicas, fisiológicas e emocionais entre as mais diversas pessoas envolvidas na observação. ] 
Entre as atividades realizadas, merecem destaque aquelas que implicaram a apresentação de questões tais como: 'Como podemos saber se o sangue se movimenta ou não?' Sendo 'pela pulsação' a resposta mais freqüente, outras questões e atividades surgiram, dentre as quais as seguintes:

debates sobre o significado da 'pulsação';

localização - no próprio corpo - de locais onde ocorrem ou são mais nitidamente percebidas as pulsações;

questionamentos diversos e trocas de idéias entre alunos/alunas e professora sobre, por exemplo, 'o que significa isso que a gente sente latejando aqui no pulso ou no pescoço?';

medidas de pulsação em aula;

medidas de pulsação de outras pessoas (atividade extra-classe);

construção de tabelas com os valores apurados pelos alunos, relacionando idade com batimento/minuto;

leitura, interpretação e discussão dos dados das diversas tabelas construídas por alunos e alunas;

construção de novo(s) gráfico(s) referente(s) à leitura, à interpretação e à comparação do grau de eficiência possível entre esses dois instrumentos (gráfico e tabela) para facilitação da visualização da leitura e da interpretação das informações obtidas por alunos, alunas e outros construtores de gráficos e tabelas.

Nessas fases de nosso estudo epistemológico-pedagógico de um modelo de ensino desenvolvido por uma professora-pesquisadora, é preciso chamar atenção para a importância atribuída à linguagem utilizada - tanto por ela quanto pelos alunos - no ensino e na aprendizagem das Ciências. Ao fazer a construção com os seus alunos de gráficos e tabelas, a professora visou o domínio da linguagem, em um sentido mais amplo, que pode ser favorecido, principalmente, pelo uso de atividades construtivas diversificadas, próprias de diferentes áreas do currículo escolar. No entanto, essa questão da linguagem, diz também respeito à importância do emprego de diferentes formas de linguagem - no caso, uma delas é a 'linguagem Matemática' de gráficos e tabelas, por exemplo - para ensinarmos os alunos a expressarem conhecimentos e informações, uma vez que um tipo de linguagem pode complementar o outro, oferecendo-nos relações de compreensão de maior número e intensidade, maior ampliação de sentidos e significados, bem como maior clareza dos diversos assuntos.

Além disso, quando abordamos o 'assunto' sangue - e esse particular nós buscamos assumir com ela - a professora sob enfoque propiciou um tipo de ensino em que considerou aspectos emocionais, sociais e culturais ligados ao 'corpo biológico' no curso da aprendizagem de seus alunos, que constituiu uma marca pedagógica clara. Isso pode ser destacado ainda, entre outras, nas atividades sobre 'as medidas do corpo', quando a professora abriu espaço em aula para trabalhar 'idéias de senso comum' manifestadas sobre as observações de

diferenças entre as pessoas de diferentes idades (idéias sobre a velhice);

características singulares de cada pessoa;

“altura” relacionada ao modo de vida e à alimentação, e à movimentação do corpo. 
Por outro lado, vale ressaltar, ainda, que a professora procurou, continuadamente, destacar algumas 'confirmações/afirmações científicas' em relação a ideias apresentadas nas discussões, como é o caso dos fatores ambientais na determinação fenotípica dos indivíduos.

Com isso, foi possível chegar ao final do estudo sobre as medidas do corpo, reafirmando a semelhança entre as proporções (de medida) da altura e envergadura, mas não entre as proporções do pé e do antebraço. E mais, concluindo (porque foi compreendido por todos) que tal semelhança na proporção de determinados itens corporais ocorre, geralmente, em indivíduos adultos. No feto, por exemplo, a cabeça tem uma proporção bem maior em relação ao corpo do que se evidencia nas fases subsequentes de desenvolvimento do ser humano.

Para finalizar, consideramos importante deixar claro que a escolha de dois modelos de ensino envolvendo alunos do $5^{\circ}$ ano das nossas escolas públicas e um terceiro realizado com alunos de classes correspondentes aos nossos anos finais do ensino fundamental, está pautada nas proposições de educadores das ciências - consideradas de relevância internacional para os avanços mais recentes no âmbito do ensino e da aprendizagem de Ciências principalmente na fase relativa ao Ensino Fundamental, dentre os quais destacam-se OSBORNE e FREYBERG (1988; 1989; 1990), e BANET e NÚÑEZ (1989; 1992; 1996). Estes, por estudarem continuadamente concepções prévias de alunos e alunas em relação aos 'conteúdos das Ciências', e mesmo concepções obtidas por eles e elas durante a instrução escolar, assinalam a semelhança existente entre as concepções de alunos e alunas de idades variadas, ou seja, que se situam - em termos de escolaridade - desde o ensino fundamental até o médio, quando se trata da compreensão do Corpo Humano.

Diante disso, justifica-se o fato de encontrarmos, geralmente, muitas dúvidas e concepções equivocadas - a respeito do Corpo Humano - persistindo ao longo da vida de muitos alunos e de muitas alunas ( bem como de muitos professores e de muitas professoras).

Com base nessas considerações, acreditamos ser possível ' iluminar a nossa prática', em quaisquer dos anos da Educação Básica, com as teorias formuladas a partir das proposições postas por estes 'modelos de ensino', bem como por outros, sabidamente bem sucedidos, realizados na perspectiva de uma abordagem de ensino construtivo nas aulas de Ciências.

Além disso, parece não haver dúvidas de que idéias básicas para a compreensão do Corpo Humano deverão ser enfocadas em diversos níveis de estudo, porém, são as estratégias de ensino - enfocadas no âmbito da ação pedagógica do 'professor-pesquisador' ou do 'professor-reflexivo' - que deverão contemplar um maior ou menor aprofundamento das idéias nesses níveis, dependendo não só da faixa etária, mas também da história da classe com a qual se estiver trabalhando.

Ao confrontar os três modelos de ensino e as várias estratégias de ensino e de aprendizagem apresentadas, é possível verificar há diferença de aprofundamento, mais especificamente, quando se trata da natureza aquisição de conceitos/concepções definidos para serem ensinados. Por exemplo, o estudo realizado com alunos e alunas dos anos finais do ensino fundamental envolveu uma preocupação maior com a 'aquisição de conceitos', demonstrando refletir aquilo que se apresentara também desde a Proposta Curricular para o Ensino de Ciências - $1^{\circ}$ grau, do Estado de São Paulo - Brasil (1992), sobre a necessidade de se construir conceitos ao longo das oito séries, mas sistematizá-los nas séries finais.

Portanto, nossos modelos inovadores de ensino - que redimensionam a nossa prática - destacam a importância de se tratar o Corpo Humano como um todo, sem perder de vista as partes, os sistemas, os órgãos, de modo que cada função realizada, quer pelas células quer 
pelos órgãos, possa se relacionar com as demais funções vitais desenvolvidas pelo organismo e que, ao trabalhar em conjunto, seja possível a compreensão de que é esta forma de 'funcionamento integrado' que nos proporciona as condições necessárias à manutenção da saúde e da vida (ARAGÃO, 2000). Por isso, ao trabalharmos com o processo da 'digestão', é preciso estabelecermos relações com outros processos - da 'respiração' e da 'circulação do sangue', por exemplo - para mostrar que, no final de todo e qualquer processo orgânico, se produz a energia necessária para o funcionamento do nosso organismo, do nosso corpo.

A questão da transformação ou do aproveitamento da energia em nosso organismo envolve, sobretudo, tratar o corpo humano como um todo integrado ao seu ambiente, numa relação compreensiva de grande abrangência e interdependência, como assinala RABELLO (2000:95) nos seguintes termos :

\begin{abstract}
...Ao privilegiar os aspectos mais gerais, de funcionamento do corpo, tornam-se essenciais as considerações acerca de fluxo de energia no ecossistema, conhecimentos nem sempre presentes nas idéias prévias dos alunos, de maneira articulada às ideias que dispõem sobre o corpo dos seres vivos. Mesmo quando os alunos possuem ideias sobre a importância da energia solar, sobre o valor energético dos alimentos (para não falar da fotossíntese) e quando admitem a transformação de calor pelo corpo humano, isto não significa que essas ideias se articulem em favor de uma compreensão global da questão, o que dificulta o processo de aprendizagem.
\end{abstract}

Tendo presente questões como essas, nos nossos modelos de ensino já são abordados não só alguns aspectos ligados às áreas biomédicas ou à ecologia, mas também aspectos sociais, culturais e emocionais/afetivos ligados ao Corpo Humano, para que seja possível a compreensão da interação deste com o ambiente, de forma tal que se possa vir a estabelecer funções e desenvolver ações que ajudem cada indivíduo a se situar nesta nossa sociedade em um novo século.

No século XXI, que ora se inicia, a sociedade global tem exigido, cada vez mais, respostas ou reações diferenciadas de cada um de nós como indivíduos, levando-nos a frequentes desequilíbrios físicos, mentais e sociais. Em função de considerações como essas, passamos a almejar - enquanto Professores e Professoras - um tipo de ensino edificante que possa efetivamente oferecer

\title{
(1) fontes de informação
}

(2) uma formação qualitativamente diferenciada para cidadãos que são os nossos alunos em formação, tendo o propósito de

(3) ajudá-los a compreender questões que são usualmente postas a cada um de nós e a obter respostas para questões que se apresentam no seu dia-a-dia, bem como vidas.

(4) propiciar-lhes, como pessoas, julgamentos e ações coerentes no curso de suas

Sendo assim, buscamos praticar um ensino que esteja relacionado com a 'aquisição de conhecimento científico' e de uma visão tanto da Ciência quanto de Biologia/Ciências tidas como parte da cultura socialmente construída ao longo dos séculos.

Temos buscado, portanto, construir com nossos alunos e alunas uma nova/outra maneira de olhar o mundo, possibilitando a cada um deles e a cada uma delas, o desenvolvimento da capacidade de pensar, de compreender, de falar, de fazer previsões e de 
agir tendo em vista a melhoria da nossa qualidade de vida, e o nosso bem comum, nossa felicidade...

Enfim, a nosso ver, é sobremaneira profícuo levarmos em conta, em termos investigativos-narrativos, abordagens alternativas de ensino - modelos de 'ensino bem sucedido' - porque, dessa forma, podemos, como Professores e Professoras, observar dinamicamente nossos alunos e alunas em suas manifestações, suas questões, suas dúvidas, ou até mesmo suas certezas, compreendendo que essas são tão importantes que podem se tornar objetos de estudo e pesquisa tanto por parte de seus colegas quanto de seu professor ou de sua professora. Parece, pois, ficar patente que um estudo educativo (ou pedagógico!) sobre o nosso Corpo Humano se constitui, em síntese, fundado em termos como os seguintes:

Da aquisição de conhecimento e de informações sobre o Corpo Humano;

Das análises de valores, de conceitos, de preconceitos e de pré- concepções;

Das discussões e da troca de idéias sobre atitudes e procedimentos para prevenção/ preservação da nossa saúde física, mental e social;

De confrontos de hipóteses e de explicações que possam expressar diferentes pontos de vista, visões do Corpo Humano;

Da busca de informações para a solução (mesmo provisória!) de problemas que, ao final, proporcionam sempre novas e significativasaprendizagens!!!

\section{REFERÊNCIAS}

ARAGÃO, R. M. R. de, SCHNETZLER, R. P. e CERRI, Y. L. N. S. (Orgs.) Modelos de Ensino: corpo humano, célula, reações de combustão. Piracicaba - SP: UNIMEP/CAPES/PROIN, 2000.

AUSUBEL, D. P. Educational Psychology : A Cognitive view .New York : Holt, Hinehart \& Winston, 1968.

BANET, E. e NÚÑEZ, F. Ideas de los alumnos sobre la Digestión : Aspectos Fisiológicos. Enseñanza de las Ciencias. 7(1), p. 35-44. 1989.

BIZZO, N. Ciências : fácil ou difícil ? São Paulo : Editora Ática, 1998.

BRASIL, MEC. Secretaria do Ensino Fundamental. Parâmetros Curriculares Nacionais : Ciências Naturais. Brasília : MEC/SEF, 1996.

BRASIL, ESTADO DE SÃO PAULO. Secretaria de Estado da Educação. Coordenadoria de Estudos e Normas Pedagógicas. Proposta Curricular para o Ensino de Ciências e Programas de Saúde - $1^{o}$ Grau. São Paulo : SE/CENP, 1992.

GUIDO, L. F. E. A Evolução Conceptual na Prática Pedagógica do Professor de Ciências das Séries Iniciais. Dissertação de Mestrado. Campinas - SP : Faculdade de Educação - UNICAMP, 1996.

MOHR, A. A Saúde na Escola : análise de livros didáticos de $1^{\mathrm{a}}$ a $4^{\mathrm{a}}$ séries. Cadernos de Pesquisa. $N^{o}$ 94, p. 50-57. São Paulo : Fundação Carlos Chagas, agosto, 1995.

NÚÑEZ, F. e BANET, E. Modelos Conceptuales sobre las Relaciones entre Digestión, Respiración y Circulación. Enseñanza de las Ciencias. 14 (3), p. 261-278, 1996.

OSBORNE, R. e FREYBERG, P. El Aprendizaje de las Ciencias : Implicaciones de la ciencia de los alumnos. Madrid : Narcea S. A. Ediciones, 1988/1989/1990/1991. 
RABELlO, S. H. dos S. Histórias de Corpo : a construção do conhecimento na sala de aula. Dissertação de Mestrado. Campinas - SP : Faculdade de Educação - UNICAMP, 2000.

SANTOS, L. H. S. dos. Incorporando outras representações culturais de corpo na sala de aula. In : OLIVEIRA, D. L. de. Ciências nas Salas de Aula. Porto Alegre : Mediação, 1997. 